\title{
THE USE OF 3D SCANNING AS A TOOL TO SUPPORT THE PRODUCTION OF AIRCRAFT COMPONENTS
}

\author{
Krzysztof ŻABA, Maciej BALCERZAK, Sandra PUCHLERSKA \\ AGH University of Science and Technology, Cracow, Poland, EU \\ krzyzaba@agh.edu.pl,maciejbalcerzak1@gmail.com, spuchler@agh.edu.pl
}

https://doi.org/10.37904/metal.2019.862

\begin{abstract}
Recently, it is possible to observe a very fast development of the optical 3D scanning methods. It is caused by the development of computer technology and optical systems whose accuracy is becoming more and more competitive in comparison to other measuring methods. Companies offer a lot of kinds of 3D scanners prepared to different applications. Scanners are different in the aspect of size of measurement area and accuracy. The most important in aviation industry is quality because all the parts installed in airplane must meet dimensional requirement. 3D scanning allows very accurate measurements of manufactured parts with accuracy up to several hundredths of a millimetre. Additionally, it is possible to identify in a full way the measured elements thanks to the fact that they are saved in the form of a three-dimensional model. This is a huge advantage from the point of view of the aviation industry because it significantly reduces the risk of making a mistake and allows conducting virtual measurements of parts even when it is already mounted on the aircraft. This method also has many applications which are supporting the production process. Examples of such applications are measurements of tools and workshop aids, digitalization of tools that were made by hand or those for which there is no dimensional documentation in the form of a 3D model, scanning of entire aircraft, virtual assembly of elements, dimensional inspection of assemblies and checking their completeness.
\end{abstract}

Keywords: 3D scanning, aviation industry, NDT applications

\section{INTRODUCTION}

For many years, it can be observed the rapid development of non-destructive methods of quality control. This is due to the wide possibilities of their applications in industry and in laboratory tests. They are very often used due to the fact that they do not adversely affect the tested material or object and can be used for tests performed on finished elements. This type of testing can be used for many types of objects and materials. Examples of applications of various non-destructive examinations are presented in articles [1-5]. Optical measurement methods that are part of non-destructive testing methods have been developed for many years. Accuracy, measurement time and ease of use of such devices were improved. An example of the application of widely understood optical methods in the case of laboratory tests is presented in the article [6]. Rapid development has also occurred in the case of 3D scanners. These are devices that use optical systems in conjunction with specially prepared software and are mainly used for quality control, reverse engineering and rapid prototyping. The huge increase in interest in these devices is caused by a significant improvement in their accuracy in recent times. Modern scanners are able to make a three-dimensional model of the tested element with an accuracy of up to $0.05 \mathrm{~mm}$. This means that they are currently a viable alternative to other measurement methods, such as e.g. coordinate machines or measuring arms. There are many companies on the market that offer various types of scanners that differ in the size of the measurement field and accuracy. Examples of comparison of 3D scanning methods are presented in the article [7]. These devices allow scanning very diverse items using small elements of the order of a few centimetres to very large objects such as airplanes. An example of scanning the entire aircraft is presented in the article [8]. From the point of view of the aviation industry, the 3D scanning method has many additional advantages. The first of these is the full traceability of the tested elements and the possibility of re-virtual measurements due to the fact that the 
measured part is saved in the form of a 3D model that can be used for additional measurements even when the part is already mounted on the plane. Another improvement that is offered by the most modern programs for operating scanners is the accuracy control with which the measurement is performed. During the measurement, the program analses successively performed scans and informs the operator with what maximum dimensional deviation they have been made. In addition, if a certain value is exceeded, a warning appears on the screen. This is a solution that significantly reduces the probability of incorrect measurement, which is very important for such responsible applications. The time of the measurement is equally important. Considering that every part installed in the aircraft requires a detailed quality control, the time necessary to measure one element is very important. In the case of small elements to create a very accurate threedimensional model of the test piece, a few minutes are sufficient. In the case of very complex, large elements, a larger amount of time is required, but in comparison to other methods, the time for measuring a single element is relatively small. There are many possibilities to use the 3D scanning method in the aviation industry. In addition to quality control of manufactured components, it can be used to control the quality of tools and workshop aids, digitization of hand-made tools or those for which there is no dimensional documentation in the form of 3D model, scanning of whole aircraft, virtual assembly of elements, dimensional inspection of assembly of parts sets and checking them completeness. These applications will be described in more detail later in the article.

\section{METHODOLOGY}

In order to obtain the proper accuracy of measurements during 3D scanning, it is necessary to follow the manufacturer's recommendations for a given scanner and apply the appropriate research methodology. On the example of the GOM Atos Core 200 scanner and software dedicated to it, an example of a research methodology allowing achieved for very accurate results will be presented. The whole test stand must include a measuring head with a suitable method of fixing so that during the tests the device is stable and immovable. Special designed tripods or elevators are used for this purpose, which ensure adequate stability during the measurement and enable scanning from different perspectives. In addition, a high-performance computing unit with installed software to operate the scanner and analysis the results obtained is necessary. It is also necessary to mount the tested elements during the measurement. The method of attachment must ensure rigid and stable fastening of the element in such a way as to enable scanning of the entire surface or the largest possible part of it. The last but equally important part of the whole station is a special plate used to calibrate the measuring head. It is very important that the scanner used for the tests passes the calibration process. In the case of 3D scanners, a calibration process is carried out in accordance with the German PTD VDI/VDE 2634 standard. In the case of tests with the use of a scanner that has the accuracy certification in accordance with this standard, we are sure that the results will be very accurate. Examples of calibration of optical systems are described in articles $[9,10]$. Even in the case of certified scanners, quick calibration performed by the operator is necessary before starting the tests. Usually, special calibration plates are used for this purpose. Calibration should be performed each time the device is moved or as often as the manufacturer specifies. In addition, GOM software informs the user about the need to perform calibration when it is necessary. During calibration, the room temperature should be measured at which the measurements will be made, because on this basis the program performs temperature compensation of the measurement. It affects the calibration of the scanner and during large fluctuations the calibration should be performed again. The scanning process itself can be implemented in two ways. Using reference points and without them. It is much more beneficial to perform measurements by sticking special points on the surfaces of the scanned element which are reference points for the software. After the first scan, the software assigns numbers to the next points and on their basis can locate the tested element in the measurement space. Of course, during measurements these points cannot move and have to be attached to the surface. Each subsequent scan must be carried out in such a way that in the measurement space there are at least three points already having the number. This allows very accurate matching of subsequent scans to the part of the model that has already been scanned. Sometimes, however, 
the use of points is impossible due to the size, shape or type of the element's surface. In this case, individual scans are matched to each other based on the geometry of the object. This method of scanning is more difficult because the program can match the scans incorrectly, so that the results will be incorrect. In addition, the shape of the element being tested must be very diverse, because the characteristic points and areas allow for accurate matching of scans and merging them into a three-dimensional model. The type of matching scans to be selected should be determined for a given element so that the quality of the model is as good as possible. Another very important aspect is the surface of digitized elements. This surface cannot be transparent because in the case of the 3D scanning method, light will penetrate through such a surface and it will not be displayed. Reflexivity is equally important. Surfaces that largely bounce light are very difficult to scan. For both types of surfaces, it is possible to use a special matting agent. It is a suspension sprayed on the tested element which creates a very thin layer that only slightly affects the accuracy of measurements and allows scanning difficult to scan surfaces. After proper selection of the method and preparation of the surface, it is possible to start scanning. The process of creating the entire three-dimensional model consists of a specific number of individual scans from different perspectives and depends on the size of the measurement field, the level of complexity of the geometry of the tested element and its size. Single scans, in the form of a point cloud in which each point corresponds to the intersection of the ray coming out from the centre of the pixel matrix in each scan with a light band projected onto surfaces, are automatically combined in the program into the entire 3D model. Such a model must then undergo a process of triangulation, that is, the processing of a point cloud into a triangle grid. After processing, the file in the form of a triangle grid, i.e. with the extension, can be used for measurements and analyses.

a)

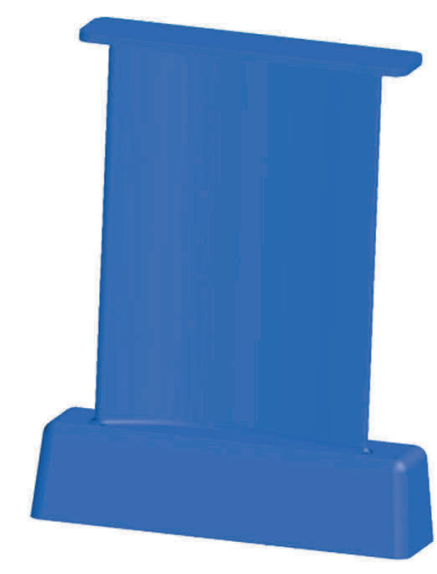

b)

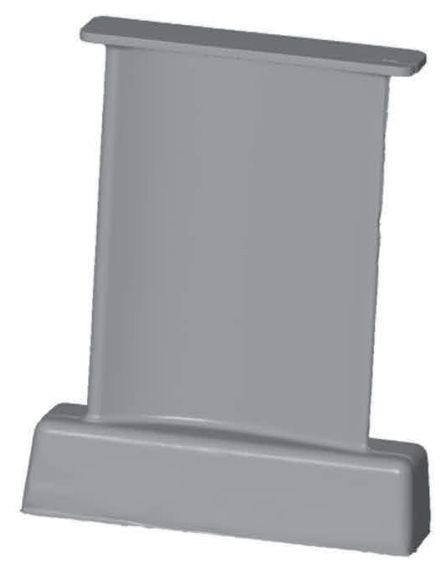

c)

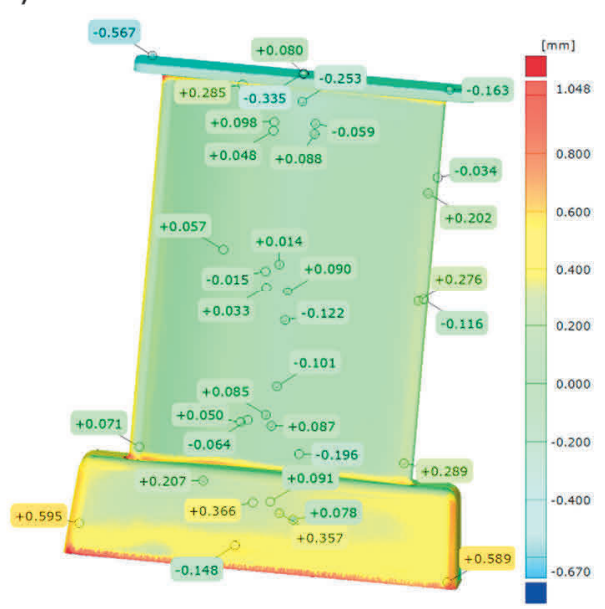

Figure 1 Comparison of the CAD model (a) to the scan (b) of the wax blade with which the blades for aircraft engines are made and the result of this comparison (c)

\section{EXAMPLES OF APPLICATION}

\subsection{Quality control}

The basic application of 3D scanners is the quality control of manufactured elements. In the case of elements mounted on an airplane, this is a key issue. Each element must be checked thoroughly so that it is not possible to mount the defective part. The 3D scanning method has many advantages, especially in the aviation industry. The quality control itself is performed by scanning the manufactured part and comparing the model obtained by scanning to the model created in CAD programs which is a reflection of the expected results. Basic result that is obtained during such a comparison is the dimensional deviation of the real part from the expected dimensions. During such a comparison, other defects of the product will also be visible, such as mechanical 
damages of the element in the form of various types of depressions or differences in the location of the drilled holes. Figure 1 presents an example of a comparison of the wax blade model scan with CAD model.

\subsection{Measurements of tools and workshop aids}

The aviation industry is characterized by a large percentage share of manual shaping of elements. This means that large amounts of workshop assistance are used. In many cases, these tools are subject to various types of deformations. 3D scanning can be used as a preliminary, roughly checking the suitability of a given tool. Each tool can be scanned and its dimensions can be checked. This can be especially useful in the case of specially prepared templates. Periodically checking the dimensions of such workshop aids can guarantee the preparation of the relevant parts when using them. An example of such an element is presented in Figure 2.

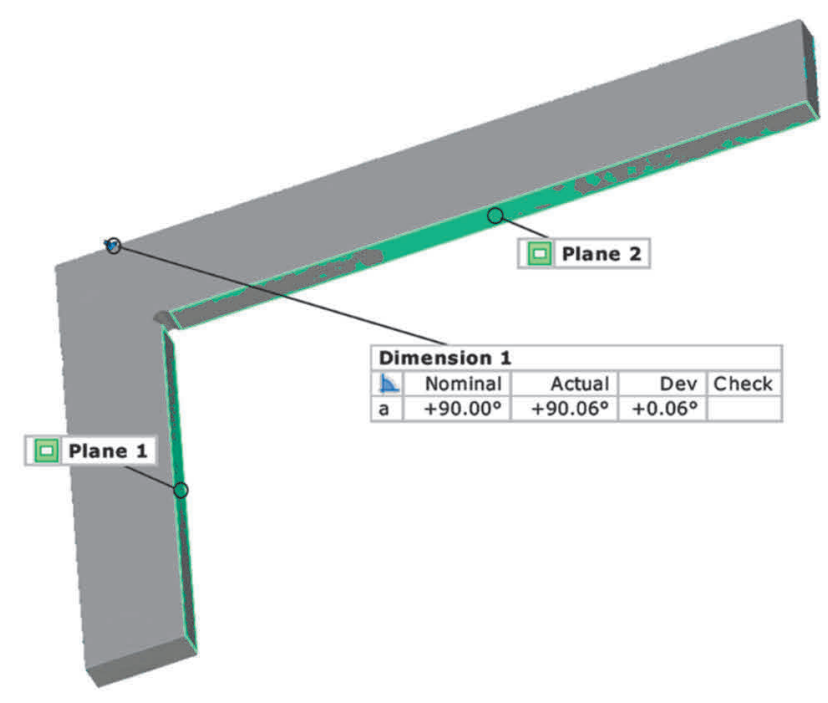

Figure 2 Example of a workshop aid scan with the determination of the angle between the arms

It is also possible to scan measuring tools. An example of a protractor scan is presented in Figure 3.

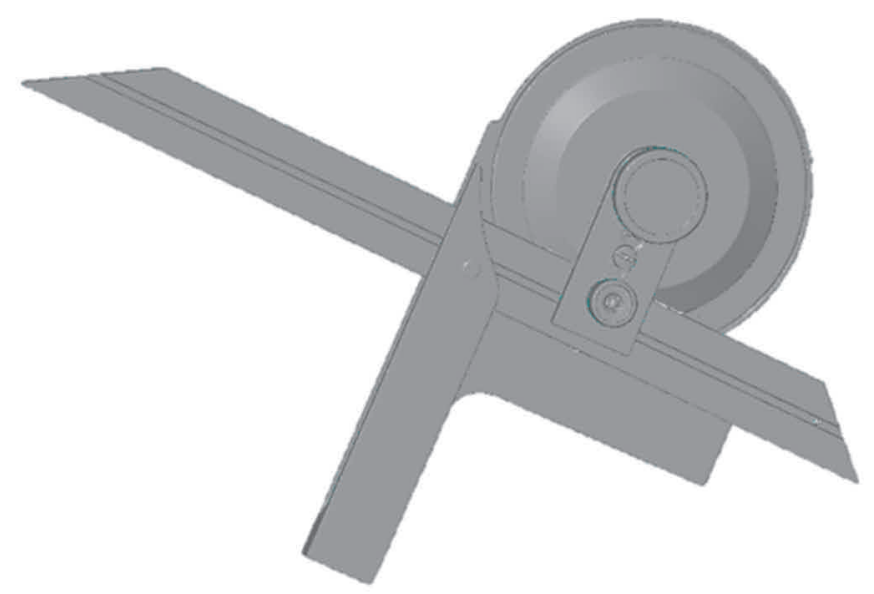

Figure 3 Example of scan of the measuring tool

\subsection{Scanning of entire aircraft}

Some 3D scanning methods allow the digitization of entire aircraft. The entire aircraft model can be used for many applications. It can be used for marketing purposes instead of two-dimensional photos. Additionally, with 
the use of such a model, various types of simulations and tests can be carried out. They can facilitate the improvement of the structure and introduction of various modifications.

\subsection{Virtual assembly of elements}

Another very interesting and useful application of the 3D scanning method is the virtual assembly of the created elements. Subsequent scanned parts can be assembled with the use of special software in order to determine their adjustment to each other. This is a very useful solution because it allows making corrections to elements that are not yet mounted to improve their matching to the other elements of the set. This action allows for a significant saving of time and money because it eliminates the need to assemble the assembly and in the case of necessary corrections to its disassembly. Of course, this solution is mostly used in the case of prototype structures. It is also possible to use 3D scanning to control the quality of assemblies created in reality. The entire set of parts can be scanned and analysed to determine dimensional deviations by comparing a set of parts actually assembled to the entire assembly made in the CAD software.

\section{CONCLUSIONS}

3D scanning is a method that has many applications in particular in the aviation industry. The increase in interest in 3D scanning methods is caused by the very rapid development of these devices and the increased availability of high-performance computer units that are necessary for the scanning process to run smoothly. In addition, the popularity of this method has a significant simplification of the interface of programs necessary for performing scans and processing results. These programs have become much more user-friendly and the person after a few days of training can independently carry out measurements. Taking into account all the aforementioned aspects and the fact that these methods are still very much developing, one can expect even greater interest in this type of devices.

\section{REFERENCES}

[1] DEANE, S., AVDELIDIS, N., IBARRA-CASTANEDO, C., ZHANG, H., YAZDANI-NEZHAD, H., WILLIAMSON, A., MACKLEY, T., DAVIS, M., MALDAGUE, X. and TSOURDOS, A. Application of NDT Thermographic Imaging of Aerospace Structures. Infrared Physics \& Technology. 2019. vol. 97, pp. 456-466.

[2] LUUKKALA, M. NDT of Polymers, Cardboard, Wood, Lumber. Encyclopedia of Materials: Science and Technology. 2001. pp. 5987-5989.

[3] MOROZOV, M., PIERCE, G., MACLEOD, Ch. N., MINEO, C. and SUMMAN, R. Off-line scan path planning for robotic NDT. Measurement. 2018, vol. 122, pp. 284-290.

[4] RESECO-BATO, M., HOR, A., RAUTUREAU, A. and BES, Ch. Impact of human and environmental factors on the Probability of Detection during NDT control by Eddy Currents. Measurement. 2019. vol. 133, pp. 222-232.

[5] HOMPSON, B. and BEGUM, S. NDT Techniques: Ultrasonic, Reference Module. Materials Science and Materials Engineering. 2017. vol. 46, pp. 245-252.

[6] AMBROSINI, D., PAOLETTI, D. and RASHIDNIA, N. Overview of diffusion measurements by optical techniques. Optics and Lasers in Engineerin. 2008. vol. 46, pp. 852-864.

[7] DEREJCZYK, K. and SIEMIŃSKI, P. Optical 3D Scanning Accuracy Check. Mechanik. 2016. Vol. 4, pp. 312-313.

[8] KACHEL, S., KOZAKIEWICZ, A., ŁĄCKI, T. and OLEJNIK, J. Zastosowanie inżynierii odwrotnej do procesu odtwarzania geometrii układu wlotowego silnika RD-33 w samolocie MIG-29. Prace Insytutu Lotnictwa. 2011. vol. 213, pp. 66-84.

[9] GĘBAROWSKI, K. and JASIŃSKI, D. Dokładność metrologiczna bezdotykowego skanera 3D wg Normy VDI/VDE 2634 -przykłady pomiarów, certyfikowanym, polskim skanerem 3D firmy SMARTTECH. In XII Forum Inżynierskie. Kraków: ProCAx, cz. II, 2013, pp. 1-7.

[10] OSTROWSKA, K., SZEWCZYK, D. and SŁADEK, J. Wzorcowanie Systemów Optycznych Zgodnie z Normami ISO i Zaleceniami VDI/VDE. Czasopismo Techniczne Mechanika, 2012. pp. 1-46. 